\title{
O CINEMA DE GUERRA DE HOLLYWOOD: A VERSÃO POLÍTICA DE UMA LINGUAGEM DE VIOLENNCIA
}

Tom Burns*

\begin{abstract}
RESUMO: Neste artigo, examina-se o cinema de Hollywood sobre a Segunda Guerra Mundial, um espaço exemplar para as representações da violência que, entretanto, estiveram sujeitas a diversas restrições de ordem política: das agências governamentais que desejavam projetar uma imagem positiva da nação e dos aliados, e dos próprios estúdios que desejavam explorar as possibilidades dramáticas do filme de guerra, mas que, ao mesmo tempo, estavam sob pressão do governo para não mostrar representaçōes realísticas que pudessem causar perturbações na frente doméstica. As imagens desfavoráveis, como o racismo e a violência extremada, foram censuradas, ao passo que um programa de imagens positivas foi esboçado pelo Escritório de Informações da Guerra (OWI) e apresentado aos estúdios.
\end{abstract}

PALAVRAS-CHAVE: linguagem de violência; censura; cinema de guerra.

D epois de o ataque japonês a Pearl Harbor (7 de dezembro de 1941) provocar a entrada dos Estados Unidos na Segunda Guerra Mundial, o presidente Franklin D. Roosevelt, sagaz em assuntos da mídia, estava ansioso por tornar o cinema um elemento importante de sua propaganda governamental no esforço de guerra. Com esse intento, diversas agências foram criadas, mas,

* Universidade Federal de Minas Gerais - UFMG. 
Burns, Tom. O cinema de guerra de hollywood: a versão politica...

em decorrência de seus esforços desordenados, concluiu-se pela necessidade de uma única agência que supervisionasse a inserção da propaganda de guerra no cinema. Com a criação do Office of War Information (OWI), em junho de 1942, o governo tencionava intervir ativamente no processo de produção cinematográfica em praticamente todos os seus niveis.

Os diretores dos estúdios de Hollywood, todavia, durante o período da guerra, receavam a interferência do governo no seu lucrativo negócio, o que provou ser uma preocupação infundada, visto que mais tarde Lowell Mellet, coordenador de Filmes Governamentais, viria lhes assegurar que o cinema de Hollywood era "um dos mais eficazes meios de informação e entretenimento de nossos cidadãos" e que deveria, portanto, permanecer livre de censura. Ele lhes disse: "Usem seu próprio discernimento ao decidirem sobre o conteúdo dos filmes” (BLUM 1976: 24-25). No entanto, como era de se prever, surgiram conflitos, muitas vezes irreconciliáveis, entre as necessidades de propaganda do OWI, que desejava uma apresentação mais positiva das questões da guerra nos filmes e a necessidade dos estúdios de produzir produtos de entretenimento que continuassem a render altos lucros.

Além das agências da sociedade civil, os militares, que dispunham de suas próprias fontes de informação e de meios de exercer pressão, também tinham alguma influência sobre o conteúdo dos filmes de guerra. Não é de se surpreender que o cinema de guerra dispensasse tratamento favorável aos militares, visto que os custos de produção de um filme de guerra eram normalmente elevados e o empréstimo de equipamentos caros, e até mesmo batalhões de soldados em atividade para servir como extras poderiam significar economia expressiva de custos. É digno de nota que em quase todos os filmes de guerra os créditos registrem inequívocos agradecimentos a uma ou outra força armada.

Para traçar suas linhas gerais para a indústria, o OWI publicou um panfleto intitulado Manual de informação do governo para a 
Rev. ANPOLL, no 21, p. 139-163, jul./dez. 2006.

indústria cinematográfica, que sugeria que os filmes fossem produzidos sob cinco categorias gerais, que podem ser assim resumidas: a primeira seção, "Por que lutamos", propunha filmes que apresentassem os objetivos positivos de guerra da nação e de seus aliados apoiados nas Guatro Liberdades de Roosevelt: liberdade de expressão, liberdade de religião, liberdade contra a carência e liberdade contra o temor. Na segunda seção, "O inimigo", o OWI expressava seu desejo de evitar a demonização de nações inteiras, mas preocupava-se com a impressão que a onipresença do inimigo poderia produzir sobre o público e com o perigo de a passividade e o pouco caso favorecerem o inimigo. A terceira seção, "As Nações Unidas", com respeito aos países aliados, propunha a produção de filmes que essencialmente não revelassem os regimes repressivos ou não democráticos entre os países aliados, e que também mostrassem que a vitória na guerra era alcançada por meio de esforço unificado. De acordo com a necessidade de unidade no esforço de guerra, a quarta seção, "A frente doméstica", ressaltava a necessidade de minimizar os conflitos étnicos, de classe, de sexo, de modo a apresentar uma frente civil unida. A quinta seção, "As forças de combate”, encorajava a produção de filmes sobre serviços auxiliares não combatentes das forças de combate e que enfatizassem a composição multiétnica de nossas forças armadas nos filmes de combate mais comoventes (KOPPES; BLACK 1990: 67-69).

Se o manual do OWI for admitido como um plano predefinido de classificação para o cinema de guerra, mas não (como de fato era sua intenção) como guia político para os produtores cinematográficos, torna-se aparente que praticamente todos os filmes poderiam ser descritos em mais de uma categoria. Por exemplo, a maioria dos filmes de combate produzidos durante a guerra pode ser classificada sob outras categorias além da categoria "As forças de combate," visto que as personagens, para cumprir sua tarefa de eliminar o inimigo, tinham geralmente de justificá-la por meio de discursos ideológicos ("Por que lutamos") ou por meio de estereóti- 
Burns, Tom. O cinema de guerra de hollywood: a versão politica...

pos raciais e nacionais ("O inimigo"). O plano também não sugeria que determinada categoria necessariamente tivesse de fornecer exemplos que evocassem a recepção pretendida. Apesar de pesquisas mercadológicas e extensivas revisões de roteiro, Hollywood não sabia o que tornaria um filme sucesso ou por quê, embora sua velha receita de ação e sentimentalismo tivesse ainda seu amplo e costumeiro apelo.

Os filmes sobre as nações aliadas tinham o objetivo de despertar a simpatia pelos cidadãos estrangeiros cuios paises foram invadidos pelos nazistas, como o combatente da resistência norueguesa (Paul Muni) em Os comandos atacam de madrugada (Commandos Strike at Dawn,1942), e a destemida garçonete (Michele Morgan) em $E$ as luzes brilharão outra vez (Joan of Paris,1942), que ajuda pilotos aliados abatidos a escapar da França ocupada pelos nazistas, ou mesmo o fracote professor (Charles Laughton), que é instigado pelos eventos a resistir à ocupação do país não identificado em Esta terra é minha (This Land is Mine, 1942), de Jean Renoir. O sentimento patriótico nacional poderia ser despertado por esses filmes mediante a identificação "naturalizada" do público americano com seu próprio passado, tanto histórico como mítico, de resistência à dominação britânica. Comentou-se que esses filmes acrescentavam "internacionalismo sentimental" ao nacionalismo sentimental (ALEXANDRE 1980: 229).

Os filmes sobre os aliados tinham, inevitavelmente, de incluir os russos, que mais tarde seriam vistos com bem menos simpatia do que os ingleses gentis de Rosa da esperança (Mrs. Miniver, 1942). Os heróicos habitantes de uma vila em $A$ estrela do norte (North Star, 1943), de Lewis Milestone, um filme aparentemente visto como uma piada na Rússia para surpresa da roteirista Lillian Hellman, bem como os resolutos lideres soviéticos de Mission to Moscow (1942) foram todos caracterizados sob uma perspectiva altamente propagandista, com Mission to Moscow chegando até mesmo a encobrir os julgamentos sumários stalinistas da década de 
Rev. ANPOLI, n² 21, p. 139-163, jul./dez. 2006.

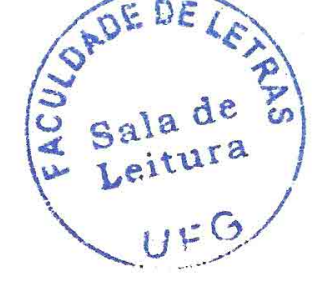

1930. Que a anticomunista Hollywood produzisse um filme de propaganda pró-soviética não é nem um pouco irônico, mas sim que a administração Roosevelt, necessitando de estimular a aliança EUARússia, participasse da produção do filme (KOPPES; BLACK, 1990: $105,200,215)$. É curioso que esse filme fosse atacado tanto pela direita (em audiências pós-guerra do Comitê de Atividades Antiamericanas do Congresso), como pela esquerda (em uma carta de notáveis intelectuais da esquerda que protestavam contra a exaltação da ditadura).

A aliança contra o fascismo também foi invocada em outros filmes: Comboio para o leste (Action in the North Atlantic, 1943) retratava um navio-tanque da marinha mercante americana comandado por Humphrey Bogart, que transportava gasolina para Murmansk. Em uma cena, os marinheiros americanos são saudados por russos amistosos que os chamam de tovarich (camarada), uma cena que se tornaria embaraçosa para a Warner Brothers durante o clima antisoviético depois da guerra, e geralmente é cortada quando o filme é exibido na televisão (KOPPES; BLACK 1990: 119). A comédia de Ernst Lubtsch To Be or Not To Be (1942) também teria de ser incluída nessa categoria, embora a caracterização de poloneses desastrados (desempenhados pelos comediantes Jack Benny e Carole Lombard) que passam a perna nos alemães, apesar de sua própria limitação, fosse vista na época como de extremo mau gosto, ainda que, surpreendentemente, considerada propaganda satírica do ministro alemão da propaganda, Joseph Goebels (SCHINDLER 1975: 45-46).

A censura, além de modificar roteiros politicamente inaceitáveis, também condenava imagens virtualmente contraditórias. Considerava-se mais confiável controlar ou cortar imagens indesejáveis do que tentar vender essas imagens pró-guerra, mesmo quando eram abundantemente produzidas. O resultado desse tipo de censura, segundo um estudioso de tais imagens, era que "as coisas não vistas tinham afinal influência tão grande sobre como o público americano percebia a Segunda Guerra Mundial, como as 
Burns, Tom. O cinema de guerra de hollywood: a versão politica...

coisas vistas" (ROEDER, 1996: 47). Por exemplo, o conteúdo dos cinejornais era também controlado: "cenas que retratavam aspectos desagradáveis da vida americana, como gângsteres, favelas, pobreza irremediável, camponeses imigrantes, etc." eram proibidas (KOPPES; BLACK 1995: 125). Não era permitida a imagem de soldados americanos mortos nos jornais ou cinejornais, pois considerava-se que tais imagens chocariam um público ainda atordoado pelo contínuo bombardeio de más notícias vindas do exterior. Somente em agosto de 1943, ou quase dois anos depois dos EUA entrarem na guerra, é que o OWI foi autorizado a publicar tais imagens, embora o próprio Davis fizesse pressão pela sua publicação, já que o governo, naquela época, considerava que tinha de contrapor a complacência doméstica, uma vez que o noticiário vindo do exterior havia melhorado, argumentando que uma maior abertura sobre a realidade da guerra combateria o ceticismo do público resultante da excessiva propaganda pró-guerra da censura repressiva de George Creel durante a Primeira Guerra Mundial.

No entanto, os censores do governo desempenharam com vigor seu papel na repressão de material fotográfico. Foram prontamente cortadas inúmeras situações percebidas com o potencial de confundir a consciência pública e contrárias a esses esforços, como: a) atrocidades visiveis eram somente cometidas pelo inimigo, de modo que mulheres idosas e crianças mortas pelo fogo amigo eram censuradas; b) a propaganda mostrava brancos e negros trabalhando juntos no esforço comum de guerra, ao passo que eram censurados os filmes que mostravam integração racial em nivel social (por exemplo, soldados negros dançando com mulheres brancas européias), bem como incidentes que retratavam conflitos domésticos; c) imagens de extrema violência física (decapitação, desmembramento, etc.) eram censuradas em nome do decoro, da necessidade de poupar os sentimentos da família e da necessidade pragmática de não desencorajar novos recrutas; d) eram proibidas quaisquer imagens que sugerissem que a guerra ou que soldados 
Rev. ANPOLL, no 21, p. 139-163, jul./dez. 2006.

individuais estavam fora de controle, como por exemplo, desordem organizacional, sexualidade e soldados em estado de choque (MAY 1996: 61-62).

Essa lista torna claro como o reputado realismo dos filmes de guerra, pelo menos daqueles produzidos durante a guerra, estava fundamentalmente comprometido pela censura. Se era praticamente impossivel fazer um filme ficcional de guerra sem retratar americanos caindo em combate, era possivel também manipular como essas imagens eram apresentadas. O que pode ser chamado de "morte em combate hollywoodiana" era, portanto, extraordinariamente imaculada e destituida de sofrimento: sem sangue, desmembramentos ou feridas abertas. Na tela, gritos de agonia deram lugar aos últimos gritos de bravura. Nenhum filme produzido durante a guerra tampouco poderia mostrar soldados em estado de colapso nervoso decorrente do estresse da guerra, embora mais de um milhão de soldados americanos - mais de três vezes o número de soldados mortos em combate - sofresse problemas psiquiátricos que os incapacitaram por algum tempo. Segundo um estudo secreto do Serviço de Saúde Pública dos EUA, o soldado regular americano sofria colapso nervoso depois de duzentos dias de combate (GILBERT 1989: 145), mas o filme Let there be light, de John Huston, continuou proibido por mais de trinta anos porque se atreveu a retratar veteranos em estado de choque (ROEDER 1996: 63).

ROEDER (1996: 48), que analisou as fotos - agora tornadas públicas - do Arquivo Nacional para descobrir o que havia sido retirado da vista pública (as imagens que os burocratas chamam de "câmara dos horrores)", observa que essas imagens foram censuradas porque tendiam a "tornar indistinta a noção entre amigo e inimigo", ou porque sugeriam que a guerra podia causar convulsões sociais, ou porque podiam minar a confiança na "capacidade dos americanos de manter sob controle suas instituições e a vida pessoal". Roeder também salienta o ponto importante em que a seleção e o controle do que poderia ser visto pelo público americano e o 
Burns, Tom. O cinema de guerra de hollywood: a versão politica...

que deveria ser retirado de sua vista, o que resultaria em uma reação potencialmente menos complexa à guerra, poderiam ter provocado graves conseqüências no pós-guerra, como a dissociação do público em relação às mortes em massa do Holocausto (nas imagens veiculadas, os corpos dos soldados americanos não poderiam ser vistos amontoados como lenha empilhada) e sua confiança desmedida (injustificada, como provou ser) na retidão moral do comportamento americano durante a Guerra Fria e no Vietnam, visto que todas as imagens de atrocidades cometidas pelos soldados americanos foram suprimidas (ROEDER 1996: 63-64.)

Com exceção das comédias sobre membros das forças armadas, os filmes produzidos sobre as forças combatentes, como anteriormente mencionado, tendem, de modo geral, ao estilo drama de combate e ação, e representam a maior parte dos filmes de guerra virtualmente produzidos. Isso é facilmente explicado. Os filmes sobre combate são inerentemente dramáticos, visto que são repletos de ação e tratam de questões relacionadas à vida e à morte, coragem e covardia, matar e sobreviver. Estruturalmente, o filme de guerra, bem como os outros tipos mencionados anteriormente, se enquadra no padrão conhecido como Estilo Clássico de Hollywood (BORDWELL; STAIGER; THOMPSON 1985), de narrativa linear e final definitivo, com a narrativa impelida pelo desejo e objetivo de uma única personagem. Geralmente mantém-se essa mesma estrutura mesmo quando o protagonista é (e invariavelmente é) membro de uma unidade coletiva, como um esquadrão ou um pelotão de infantaria, porquanto essas unidades, caracteristicamente, abarcam conflitos internos que são controlados por um indivíduo de personalidade forte (o sargento durão, o oficial comandante compassivo), cuja finalidade é alcançar um objetivo coletivo que normalmente inclui: chegar em segurança a um destino, resgatar outros soldados ou civis, defender uma posição, ganhar uma batalha, escapar de uma prisão ou uma combinação desses elementos. 
Rev. ANPOLL, $\mathrm{n}^{0} 21$, p. 139-163, jul./dez. 2006.

Deve-se observar que essa fórmula geral ainda se mantém válida mesmo em filmes recentes de guerra, como O resgate do soldado Ryan (Saving Private Ryan, 1998), de Steven Spielberg, que mostra o conservadorismo essencial do gênero. Embora o filme de Spielberg comece com imagens de extrema violência (o Dia "D" na praia de Omaha, onde havia $70 \%$ de baixas), como estripação e mutilação, que não seriam permitidas aparecer nas telas da época da guerra, sua trama segue linhas bem similares: a pequena unidade (um esquadrão desintegrado), comandada por um oficial consciencioso (Tom Hanks), chega ao seu destino, onde lhe é dada a missão de resgatar um soldado. A unidade cumpre sua missão depois de obstáculos e reveses (primeiro, uma identificação equivocada, cômica, e em seguida um atirador de elite inimigo e um outro com uma metralhadora que provocam a morte de dois membros do esquadrão). O soldado é finalmente encontrado no vasto campo de batalha, mas o esquadrão, por fim, tem de ajudar a defender uma posição diante do contra-ataque alemão (segunda maior seqüência de ação), ocasião em que o oficial morre heroicamente, sacrificando efetivamente sua vida pela vida de outro homem.

Como visto nesse exemplo, o objetivo coletivo do filme de guerra pressupõe a unidade de esforços contra determinada resistência. A representação de soldados na linha de frente empenhados em alcançar o bem comum por meio da realização de um objetivo era, por conseguinte, importante, mesmo que isso significasse, no filme de combate pós-guerra, a representação mais sutil das mensagens ideológicas ou moralistas do filme produzido durante a guerra, na forma de compromisso com o dever e com os colegas soldados, embora essas também fossem motivações importantes das personagens dos filmes de combate em tempo de guerra. A difundida presença de pelotão étnico matizado no filme de guerra tinha a intenção, no sentido estrutural, de mostrar a necessidade de transcender diferenças em favor do compromisso com a causa comum. Pode-se também ver isso como uma forma de incluir na categoria 
Burns, Tom. O cinema de guerra de hollywood: a versão política...

"As forças de combate" os aspectos ideológicos pressupostos nas categorias de filme "Por que lutamos" e "A frente doméstica", de acordo com o conteúdo desejado pelos propagandistas do governo. A mera presença de homens de diferentes origens nacionais e étnicas unidos em um esforço comum, especialmente quando era difícil imaginar em que outras circunstâncias poderiam estar tão unidos, constituía-se expressão eloqüente da noção sociológica de "mistura das raças", tão preciosa ao mito da América "terra dos seres livres" e, no entanto, tão distante das realidades dos conflitos raciais e étnicos presentes nas ruas do país durante a guerra, como os distúrbios raciais conhecidos como os zoot-suit riots de Los Angeles, e mesmo dentro das forças armadas (OTLEY 1995: 434-452).

Em contraste com o filme dramático produzido durante a guerra, a violência da guerra não pode ficar fora da tela. Pode-se mesmo dizer que a violência constitui parte importante de seu apelo de permitir ao espectador experimentar as emoções apresentadas na tela. Em gêneros, como o western e os filmes de gângsteres, também caracterizados por ação violenta no tema central, a violência tinha de ser explicada ou justificada tematicamente: desordem social, falta de controle, ganância individual, desejo de vingança são algumas dessas justificativas (WARSHOW 1992: 465-466). Em contraste, o filme de guerra é o espaço cinematográfico onde a violência pode ser destituída de qualquer fundamento, até mesmo quando excessiva, porque ela não é um subproduto da guerra, mas exatamente o seu fim, e a violência na guerra é a mais letal porque é propagada em vasta escala.

Ademais, ao passo que a violência pode ser justificada em nivel nacional ou internacional, ela também pode ser excessiva (isto é, ultrapassar os limites esperados) em nível localizado em razão de circunstâncias como caos e ruptura, decorrentes de batalhas travadas entre populações civis. As emoções humanas, como reconheceu o teórico de guerra Clausewitz, fogem ao controle durante a 
Rev. ANPOLL, n² 21, p. 139-163, jul./dez. 2006.

guerra, e a violência pode voltar-se contra aqueles que não a instigaram.

Mesmo quando não há clima de ódio nacional e de animosidade, o combate por si só instigará sentimentos hostis: a violência cometida por ordens superiores incitará o desejo de vingança e retaliação contra aqueles que a perpetraram, e não contra os poderes que ordenaram a ação. Os teóricos conseguem observar o combate de forma abstrata, como um teste de força destituído de emoções. (CLAUSEWITZ 1976: 138.)

Não obstante essas possibilidades reais, a violência representada nos filmes de combate feitos durante a guerra tende a ser emudecida. A razão, como sugerida anteriormente, é politica. Esses filmes não eram tanto veículos de ação e espaços para a violência, como eram veículos de propaganda que retratavam o patriotismo e o espírito de luta dos rapazes no exterior. Não se poderia permitir que a violência do filme de combate em tempo de guerra, como parte indispensável à representação do patriotismo e do empreendedorismo nacionais, fosse vista como gratuita, como de fato era, e nem mesmo nas versões cinematográficas do pós-guerra. Como observou WALSH (1982:1), os filmes e outras mídias não "representam as realidades da guerra, mas normalmente tendem a gerar em vez disso, uma nova classe de mitos inautênticos e turvos."

Um de tais mitos é o mito da guerra como elemento formador da experiência adulta, algo que não é novo nem na ficção e nem no cinema, mas que geralmente é ressuscitado no filme de guerra e que continua a exercer influência perniciosa na mente dos jovens. Nas circunstâncias da guerra tecnológica moderna, esse mito torna-se tão suspeito que produz uma contranarrativa: o jovem, originalmente idealista, torna-se agora desiludido. Esse é, de fato, o tema 
Burns, Tom. O cinema de guerra de hollywood: a versão política...

mais comum da ficção e das narrativas cinematográficas da Primeira Guerra Mundial e da Guerra do Vietnã, ambas as guerras vistas como impopulares e travadas sobre fundamentos ideológicos duvidosos. Esse padrão também se mantêm válido na ficção e nos relatos da Segunda Guerra Mundial, mas por meio das pressões ideológicas exercidas sobre as representaçōes cinematográficas da guerra e por meio da diferença real percebida dessa guerra como uma travada contra o fascismo, o que normalmente provocava uma inversão do padrão: os protagonistas dos filmes sobre a Segunda Guerra Mundial estavam mais inclinados a aumentar, e não a diminuir, seu idealismo no curso de sua experiência. Com freqüência, o jovem soldado, indiferente às causas da guerra, toma consciência da importância de sua participação, um tipo de amadurecimento como cidadão de uma nação democrática.

Para que essas questões ideológicas se manifestassem no filme de guerra, a violência tinha, na verdade, de ser representada de modo mais sutil ou restrito. Um dos resultados de se sub-representar a extrema violência dos combates, no entanto, é que os filmes feitos durante a guerra sacrificavam o realismo (ferimentos, sangue, mutilação e morte) em favor da propaganda, uma vez que a representação de violência extrema sofrida pelos soldados americanos ou por eles perpetrada era considerada contraproducente. Até mesmo os cinejornais, apresentados durante os intervalos dos filmes nos cinemas, e que tiveram seu apogeu durante a guerra (e somente foram descontinuados na década de 1960 quando não conseguiam mais competir com a cobertura da televisão), eram fortemente censurados de modo a suprimir os aspectos mais cruéis da guerra. Muito à semelhança dos filmes ficcionais, os cinejornais censurados, supostamente factuais, ajudaram a manter os mitos heróicos.

Relacionado com o filme de guerra como propaganda, colocava-se um problema historicamente específico: nos primeiros anos da guerra, os produtores cinematográficos tiveram de reconhecer 
Rev. ANPOLL, n²1, p. 139-163, jul./dez. 2006.

que os eventos não favoreciam as forças americanas em sua luta contra os japoneses (e nem haviam ainda descoberto o recurso de se fazer uma total revisão histórica da realidade, como visto em diversos filmes sobre a Guerra do Vietnã). Elmer Davis, diretor da OWI, considerava que o povo americano conseguiria aceitar a verdade sobre as baixas e perdas, mas os militares discordavam, e esse ponto de vista foi mantido. Os estúdios, cientes de que o público não tem fantasias de perdas, mas também cientes de que o público não poderia ignorar totalmente a verdade das más notícias, comprometeram-se com a fórmula de deixar a vitória em suspensão, como visto nos filmes Nossos mortos serão vingados (Wake Island, 1942) ou Bataan (1943). Essas duas batalhas foram historicamente derrotas militares. Nos filmes produzidos sobre essas duas batalhas, os americanos são representados como que lutando em uma ação mantida em suspenso, em que a derrota não se repercute, mas é apenas temporária. Esse procedimento de narrativa do filme afirmativo de guerra é chamado de "lógica determinada do futuro", fundamentada na distinção entre uma narrativa imprevisível de contingência (isto é, os eventos voláteis da própria guerra) e "uma narrativa organizada e 'preordenada' em que a força de uma lógica controla os eventos" (POLAN 1986: 51).

Se o filme Nossos mortos serão vingados começa fazendo uma ligação com o passado, com uma alusão à suposta derrota heróica de General Custer na batalha de Little Big Horn (talvez sugerindo uma equiparação racial do massacre de americanos por índios e por japoneses), seu final vislumbra o futuro. O filme chega até mesmo a sugerir que o sacrificio daquelas vidas humanas tornou possivel as vitórias americanas no Pacífico (momento em que a voz do narrador invisivel promete "uma vingança justa e terrivel"). O evento histórico é, portanto, visto em retrospectiva, projetado a partir de um futuro mais brilhante e conhecido sobre um passado mais escuro, cuja funesta ameaça não se concretizará. Como observado por Polan, "a narrativa torna-se o lugar privilegiado de um final sig- 
Burns, Tom. O cinema de guerra de hollywood: a versão política...

nificativo; o prólogo pressupõe e até mesmo determina o epílogo" (POLAN 1986: 47).

Tanto Nossos mortos serão vingados como Bataan foram elogiados na ocasião porque traziam um novo "realismo" às suas cenas de combate, o que provou ser a coisa menos verdadeira que se poderia ter dito a respeito desses filmes. Nossos mortos serão vingados conta a ação histórica de menos que 400 fuzileiros navais que resistiram a uma força inimiga muito maior antes de ser aniquilada (o desembarque inicial em 11 de dezembro de 1941 foi repelido, mas a ilha foi conquistada em 23 de dezembro). As cenas da bataIha, a despeito das hostes de tropas japonesas que avançavam como hunos bârbaros, foram apropriadamente descritas como dispondo de uma "qualidade esterilizadora que fez a guerra mais parecer a um grande campo de futebol do que um encontro mortal" (KOPPES; BLACK 1990: 256). Bataan relembra as tropas americanas e filipinas capturadas em abril de 1942 na península de Bataan, nas Filipinas, e que foram submetidas à infame marcha da morte a um campo de prisioneiros. Nesse filme, a marcha da morte não é nem mesmo mostrada: em vista da realidade da derrota e de seu valor como propaganda negativa, o que Bataan oferece ao espectador, bem como outros filmes sobre a Batalha do Álamo, é uma heróica resistência atê o último homem, com o objetivo de ilustrar a lógica determinada do futuro.

O sargento Bill Dane (Robert Taylor) reúne homens de diferentes unidades, a maioria especialista não combatente (o tema familiar do oficial durão e experimentado, lidando com homens inexperientes) com a missão de deter o avanço do exército japonês. O pequeno esquadrão cava trincheiras na margem distante de um rio, detona uma ponte e aguarda o inimigo, com o objetivo de impedir que reconstrua a ponte e que desloque tropas e equipamentos pesados adiante. Embora atiradores de elite japoneses eliminem gradualmente o número de combatentes e o moral da tropa, esta detém o que parece ser uma unidade do tamanho de um batalhão, 
Rev. ANPOLI, n² 21, p. 139-163, jul./dez. 2006.

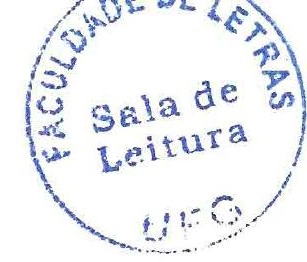

talvez ainda maior, uma vez que o "enxame amarelo" não dava sinais de interromper sua marcha. O combate homem a homem é burlesco, e há até mesmo um momento de música de violino em segundo plano enquanto o sargento arruma tempo para ditar uma carta em que afirma o valor de morrer pela liberdade, visto que seus homens tiveram um bom desempenho e morreram em ação (um de malária). Alguns dos homens são a favor de uma retirada antes que sejam totalmente aniquilados, uma atitude bastante sensata em vista das circunstâncias, mas o sargento Dane nega-se a abandonar seu posto. Na última cena, ele dispara sua submetralhadora Thompson contra as forças inimigas que avançam, convidando-as a "vir e levar chumbo". A imagem se desvanece gradualmente antes que ele seja morto, o que simbolicamente representa uma negação do massacre que de fato ocorrera.

O padrão "resistência até o último homem" continua válido em um exemplo posterior, Sahara (1943), mas como o general Montgomery derrotara os alemães na África do Norte, torna-se possivel mostrar o inimigo como definitivamente reprimido. Nesse filme, um destacamento de tanques americanos junta-se ao $8^{\circ}$ Exército Britânico na África do Norte. O sargento Gunn (Humphrey Bogart) é isolado com seu tanque M-3 e sua equipe e cercados por três lados; ele é o durão solitário, sem família a não ser o exército, que conversa com seu tanque como se este fosse uma mulher, mas que ainda é capaz de mostrar compaixão (ele salva de morte no deserto um prisioneiro de guerra italiano). Os estereótipos nacionais são apresentados no emotivo italiano, no arrogante alemão, no sarcástico francês, no negro obediente (um sudanês associado com os britânicos que, numa inversão do mito ariano, mata o fugitivo alemão em uma luta corpo-a-corpo) e em alguns afáveis anglófonos: um irlandês, um inglês e um sul-africano; em outras palavras, uma versão internacional do pelotão étnico.

Em uma reprise de Bataan, esse microcosmo das forças aliadas, depois de um instigador discurso de Gunn, cava uma trinchei- 
Burns, Tom. O cinema de guerra de hollywood: a versão politica...

ra em um oásis do deserto, e com coragem e uso de um estratagema detém o ataque de um batalhão alemão de 500 homens. A aniquilação inevitável das forças aliadas não é mostrada na tela, mas justificada como sacrifício necessário para repelir o avanço inimigo. Talvez para responder ao ceticismo do público quanto a essa probabilidade numérica, o médico oferece uma explicação ideológica: "Somos mais fortes, eles nunca tiveram a dignidade da liberdade". Em um final camp, os capacetes dos homens mortos inclinamse em aprovação quando a voz de Gunn diz: "Nós os deteremos em El-Alamein". Pode ser um sinal de perpetuação de mito cinematográfico o fato de que a refilmagem de Sahara (com James Belushi no papel do sargento Gunn) seja meramente a reprodução fiel da versão antiga, como se não somente a batalha como também o próprio filme sobre a batalha merecessem comemoração.

O diário de Guadalcanal (1943) baseado no best-seller de 1943 do correspondente de guerra, Richard Tregaskis, é outro exemplo de como o filme de combate em tempo de guerra retratou de forma precária a realidade histórica. O documentário This is Guadalcanal (1942) mostra que a batalha foi uma campanha por terra, mar e ar que durou seis meses, com embates corpo a corpo à noite, malária, e 7 mil baixas americanas e 25 mil japonesas. Embora a vitória fosse finalmente alcançada, a longa, suja e cara campanha na selva da primeira divisão de fuzileiros navais é raramente citada em $O$ diário de Guadalcanal, onde a referência ao sofrimento e às perdas de homens é geralmente feita pela voz do narrador invisível do correspondente de guerra (Preston Foster), cujas palavras portentosas contrastam de forma nada dramática com os gracejos dos soldados. Os japoneses apenas oferecem uma leve resistência ao avanço americano e praticamente não há sangue, o que é um insulto aos combatentes históricos de ambos os lados: os soldados atingidos simplesmente rolam ou caem, embora os atiradores de elite japoneses sofram quedas espetaculares de árvores, o que, pelo menos, deu emprego a dublês. O filme, no entanto, notabiliza-se pela intro- 
Rev. ANPOLL, n ${ }^{\circ}$ 21, p. 139-163, jul./dez. 2006.

dução de algumas personagens clichês dos filmes de guerra: o oficial comandante compassivo (Richard Conte) e o sargento durão (Lloyd Nolan), que mantêm elevada o moral da tropa; o soldado engraçado (William Bendix), que brande um cassetete como se o combate na selva fosse simplesmente uma extensão das brigas barulhentas da cidade grande; o latino ardente (Anthony Quinn); e o jovem imberbe (Richard Jaeckel) que amadurece durante o combate, atingindo a virilidade.

Outro clichê, mais danoso, pode ser visto em $O$ diário de Guadalcanal e na maioria dos filmes em que os japoneses são o inimigo. O temivel soldado japonês, que somente o narrador parece respeitar como um combatente da selva, é referido com epítetos de menosprezo racial ("macacos," "olhos rasgados"). Em uma cena notável, o jovem expressa ansiedade quanto ao problema moral de ter que matar pessoas na guerra, ao que o sargento responde com a simples racionalização: "Aquilo não é gente". De modo similar, em Um punhado de bravos (Objective Burma, 1945, os homens descobrem uma unidade de companheiros que foi morta e mutilada pelos japoneses. Um correspondente de um jornal presente faz um discurso sobre a natureza degenerada do inimigo: "Fétidos e insignificantes selvagens. Acabem com eles [...] varram-nos da face da terra" - o que relembra com desconforto a nota que o Sr. Kurtz, em O coração das trevas, o romance de Joseph Conrad, ironicamente rabisca ao final de seu relatório para a Sociedade Internacional para a Supressão dos Costumes Bárbaros: "Exterminem todos os bárbaros!"

Essa racionalização do ato de matar tendo o inimigo como subumano recorre com freqüência no filme de combate hollywoodiano em tempo de guerra, no qual os japoneses são o outro racial, enquanto os alemães são "como nós," embora motivados por uma ideologia do mal. Em ambos os casos, o inimigo é demonizado para sejam removidos todos os obstáculos ao seu aniquilamento, uma solução que também deve funcionar para o público espectador, que deve assistir a tais ações e aprová-las. Por exemplo, o filme The 
Bunns, Tom. O cinema de guerra de hollywood: a versão politica...

purple heart (1944), sobre pilotos americanos capturados que são torturados e executados por interrogadores perversos, "tinha como objetivo acirrar o ódio pelos japoneses em um momento em que parecia que a guerra na Europa ocupava todas as manchetes" (SCHINDLER 1975: 82.) Deve-se ressaltar aqui que, mesmo em filmes anteriores, como Bataan e Nossos mortos serão vingados. são os próprios americanos que estão dispostos a "lutar até o último homem", os quais, nesses filmes, são representados em heróica ação de resistência, uma versão atualizada dos espartanos nas Termópilas. Em outros filmes de combate, tal tenacidade é rotulada de suicida e atribuida a raças "fanáticas" como a japonesa.

Embora pareça até um certo ponto necessária a demonização do inimigo durante a preparação psicológica dos soldados para o combate - uma vez que são homens criados como civis e com escrúpulos morais quanto a matar, sendo necessário que aprendam, de algum modo, a fazê-1o - a representação caricaturesca, unidimensional, com o objetivo de despertar nos civis emoções contra o inimigo, o que foi feito com freqüência nos filmes e propaganda visual durante a guerra, é outra questão. Por exemplo, em pôsteres de propaganda de diferentes épocas, o inimigo é representado como forasteiro, agressor, torturador, estuprador, animalesco, insignificante e a própria morte (KEEN 1998: 1-81.). Colocando de lado as objeções morais, tal estereotipagem pode ser politica e esteticamente contraproducente, como revelado no pertinente comentário feito por Caroline Lejeune, critica britânica do cinema produzido durante a guerra ao jornal The Observer (1 de novembro de 1942):

Depois do filme 48 horas [Went the day well?], fui para casa um tanto triste e fiz algumas reflexões sobre os filmes de guerra em geral. A primeira é que um filme que exalta o espírito britânico, como faz e continuará fazendo a maioria dos filmes dessa época, será obviamente mais eficaz se apresentar nossos inimigos com uma medida razoável de moderação. 
Rev. ANPOLL, no 21, p. 139-163, jul./dez. 2006.

É perigoso mostrar seus adversários como palhaços ou fanfarrões que somente alcançam seus objetivos por meio de traição, força bruta ou mero acaso. Um diretor que assim procede estará simplesmente menosprezando seus próprios compatriotas, uma vez que a vitória sobre esses povos será representada como vazia e mediocre. (Apud ALGATE; RICHARDS 1994: 134-135).

O mesmo é válido, mutatis mutandis, para o cinema de Hollywood quando trata do esforço militar americano, bem como para as diversas obras literárias populares sobre o período da guerra de autores norte-americanos como John Steinbeck, Helen McInnes, Glenway Wescott, Upton Sinclair, e o inglês Nevil Shute, que exploram a dicotomia moralmente simplista do filme de guerra de Hollywood. (BLUM 1976: 48-52.) Os riscos, como inferidos pelos comentários da crítica, a perda de eficácia dramática e a conseqüente perda de credibilidade da história também sugerem uma redução proporcional na eficácia da mensagem propagandista: considera-se que somente uma vitória sobre um inimigo verdadeiramente extraordinário pode valer a pena. De fato, uma dos atrativos para Hollywood demonizar o inimigo era exatamente a possibilidade dramática simplista do cenário bom versus mau. A guerra tecnológica moderna dificilmente pode ser humanizada, o que a torna ainda mais dificil de ser dramatizada. Somente um documentário poderia tentar mostrar a impessoalidade ou a desconcertante complexidade que os veteranos de guerra e os romancistas de guerra sérios perceberam como a natureza da guerra, e mesmo esses tipos de obras procuram encontrar um ângulo pessoal e dramático.

Por sua parte, o OWI tentou minimizar o racismo na retratação dos japoneses ao insistir com os estúdios no conceito de fascismo para explicar os japoneses como um inimigo nocivo, embora esse conceito não fosse historicamente ou conceitualmente aplicável ao governo japonês (PAYNE 1995: 328-337). Além de sua ideologia 
Burns, Tom. O cinema de guerra de hollywood: a versão política...

liberal, anti-racista, o OWI tinha uma preocupação menos nobre e mais política com a identificação dos japoneses por raça, uma vez que alguns negros americanos e muitos outros povos em paises asiáticos colonizados identificavam-se com os japoneses como povos "irmãos de cor que estavam livrando-se do domínio do homem branco" (KOPPES; BLACK 1990: 250). Uma visão mais politizada do inimigo asiático como militarista, adorador de imperador e, mesmo, fascista poderia, talvez, compensar essas identificações perigosas, no entanto, Hollywood não conseguia resistir à imagem odienta do "japa sanguissedento, dentuço e cambaio". Muito provavelmente, os filmes simplesmente refletiam a opinião pública, visto que uma pesquisa de opinião feita em 1942 revelou que os americanos percebiam os japoneses como "traiçoeiros, astutos, cruéis e beligerantes" (BLUM 1976: 46).

O aspecto racial dessa percepção, entretanto, pode ser exagerado, uma vez que a mesma pesquisa mostrou que os chineses, i.e., membros de uma nação aliada, eram vistos como "diligentes, honestos, valentes e religiosos", ou seja, bem parecidos como os americanos provavelmente percebiam a si mesmos. O fato de que os americanos podiam distinguir entre uma nação oriental "boa" e outra "má" sugere que a propaganda politica pró-aliados e a propaganda racista antijaponesa eram eficazes na criação dessas percepções. Mas, de qualquer modo, a preferência de Hollywood pelo racismo como apelo maior que a representação política pode ser vista na ausência de um equivalente japonês do "alemão bom" nos filmes de guerra. Embora os alemães fossem o inimigo que propagava uma ideologia racista e a executava em seus campos de concentração, o soldado americano via o alemão como alguém perecido consigo, e o público americano, pelo menos nessa ocasião, não tinha consciência ou era indiferente ao programa nazista para a Solução Final.

Provavelmente, a única forma eficaz de superar essa ausência de representação realista do inimigo era simplesmente 
Rev. ANPOLL, $\mathrm{n}^{\circ}$ 21, p. 139-163, jul./dez. 2006.

apresentá-lo como invisível e concentrar-se nos homens que o combatiam, uma estratégia que William Wellman empregou em The story of G.I. Joe (1945), amplamente considerado como o melhor filme de combate feito em Hollywood durante a guerra. O filme era uma adaptação da obra não ficcional Here is your war, de Ernie Pyle, o correspondente de guerra americano amado pelos soldados de infantaria por compartilhar de suas agruras. O filme faz uma homenagem a Pyle, que no filme é personagem (protagonizada por Burgess Mereidith) e narrador invisivel, e aos soldados, fugindo da costumeira comédia manca, da linguagem grandiloqüente vazia da retórica patriótica, em favor de uma representação naturalista da vida do soldado americano. Com imagens que mostram Pyle arrastandose pela península italiana em direção a Roma com os dogfaces da

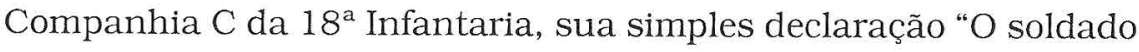
da infantaria vive tão miseravelmente e morre tão miseravelmente" ganha significado de forma tocante. Os vivos são retratados nos homens estuporados de fatiga enquanto marcham sob chuva, no fogo de artilharia durante a noite, nos embates de casa em casa, e até mesmo no dramático episódio do sargento que ao tentar ouvir a voz de seu filho bebê em uma gravação tem um colapso nervoso, mas os mortos, pelo menos na forma das "mortes de Hollywood", estão ausentes. Os mortos são retratados sem ornatos ou as baixas são informadas por meio de relatórios lacônicos. Ao restringir as cenas de ação (um notável exemplo é a seqüência discreta do atirador de elite alemão na torre da igreja), o filme, paradoxalmente, ganha mais força. Não há nenhuma atitude de triunfalismo. O corpo do oficial comandante, capitão Walker (Robert Mitchum), é levado de volta ao acampamento sobre uma mula depois de uma batalha não mostrada na tela - o fim inglório de um respeitável oficial que se preocupava com o bem-estar de seus homens. A mensagem específica de que na guerra os homens bons geralmente encontram seu fim em mortes claramente não heróicas não faz parte da propaganda, e talvez somente fosse possivel em um filme de comba- 
Burns, Tom. O cinema de guerra de hollywood: a versão política...

te produzido no último ano da guerra (traduzido do texto em inglês por William Alkmin).

\begin{abstract}
This article examines the Hollywood film about the Second World War, an exemplary site for representations of violence, which were, however subject to a number of political restraints: from the government agencies, which wanted to project a positive image of the nation and the Allies; and from the studios themselves, which wanted to exploit the dramatic possibilities of the war film but at the same time were under pressure from the government not to show "realistic" representations that might cause disturbances on the home front. Unfavorable images like racism and extreme violence were repressed while a program of positive images were outlined by the Office of War Information and offered to the studios.
\end{abstract}

KEY WORDS: language of violence; censorship; war films.

\title{
BIBLIOGRAFIA
}

Alexander, C. C. (1980). Here the country lies: nationalism and the arts in twentieth century america. Bloomington: Indiana University Press.

Algate, A.; Ricards, J. (1994). Britain can take it: the british cinema in the second world war. Second Edition. Edimburgo: Edinburgh University Press.

Buum, J. M. (1976). V was for victory: politics and american culture during world war II. Nova Iorque: Harcourt, Brace, Jovanovich.

Bordwell, D.; Staiger, J.; Thompson, K. (1985). The classical american cinema: film style and mode of production to 1960. New York: Columbia University Press.

Clausewitz, K. von. (1976). On war. Ed. e trans. Micheael Howard e Peter Paret. Princeton: Princeton University Press.

Gilbert, M. (1989). The second world war: a complete history. New York: Holt. 
Rev. ANPOLL, no 21, p. 139-163, jul./dez. 2006.

KEEN. (1998). Faces of the enemy: reflections of the hostile imagination. Nova Iorque: Harper's Row.

Koppes, C.; Black, G. (1990). Hollywood goes to war: how politics, profits and propaganda shaped world war II movies. Berkeley: University of California Press.

MAY, L. (1996). Making the american consensus: the narratives of conversion and subversion in world war ii films. In: ERENBERG, Lewis, HIRSCH, Susan E. The war in american culture: society and consciousness during world war II. Chicago: University of Chicago Press. p. 71-102.

Otley, R. (1995). Negroes are saying... african-americans and the war: discrimination and protest, 1942. In: Reporting world war II: part I. New York: The Library of America, p. 434-452.

PaYne, S. G. (1945). A history of fascism 1914-1945. Madison: University of Wisconsin Press.

Polan, D. (1986). Power and paranoia: history, narrative, and the american cinema 1940-1950. New York: Columbia University Press.

Roeder JR., G. H. (1996). Censoring disorder: american visual imagery of world war II. In: ERENBERG, Lewis; HIRSCH, Susan E. The war in american culture: society and consciousness during world war II. Chicago: University of Chicago Press. p. 46-70.

SCHINDLER, C. (1979). Hollywood goes to war: films and american society 1939-1952. London \& Boston: Routledge \& Kegan Paul.

WALsh, J. (1982). American war literature: 1914 to Vietnam. St. Martin's Press, 1982.

WARSHOw, R. Movie chronicle: the westerner. In: Gerald Mast, Marshall Cohen, Leo Braudy (Ed.). Film theory and criticism: introductory readings. $4^{\text {th }}$ edition. Oxford: Oxford University Press, p. 463-468.

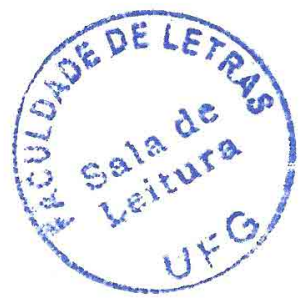

